\title{
PENGARUH MODEL PEMBELAJARAN PROBLEM POSING DENGAN PENDEKATAN REALISTIK TERHADAP KEMAMPUAN KOMUNIKASI MATEMATIS MAHASISWA
}

\author{
H. Hodiyanto, Rahman Haryadi \\ Fakultas Pendidikan MIPA dan Teknologi IKIP PGRI Pontianak, Indonesia \\ Email: haudy_7878@yahoo.com
}

\begin{abstract}
ABSTRAK
Berbagai hasil penelitian menunjukkan rendahnya kemampuan komunikasi matematis siswa maupun mahasiswa dan salah satu faktor yang paling berpengaruh adalah model yang selama ini diterapkan masih belum optimal. Oleh sebab itu, perlu dicarikan solusi untuk mengatasi permasalahan tersebut dan salah satu model yang dapat diterapkan untuk mengatasi permasalahan adalah model pembelajaran problem posing dengan pendekatan realistik. Adapun tujuan dalam penelitian ini adalah untuk mengetahui pengaruh model pembelajaran problem posing dengan pendekatan realistik terhadap kemampuan komunikasi matematis mahasiswa. Teknik pengambilan sampel menggunakan teknik cluster random sampling dan kelas B Pagi semester II Program Studi Pendidikan Matematika sebagai sampel penelitian. Teknik pengumpul data menggunakan pengukuran, sedangkan alat pengumpulan data yang digunakan berupa tes kemampuan komunikasi matematis berbentuk esai. Teknik analisis data menggunakan statistik inferensial berbantuan software SPSS 16. Berdasarkan hasil analisis data dapat disimpulkan bahwa model pembelajaran problem posing dengan pendekatan realistik berpengaruh yang signifikan terhadap kemampuan komunikasi matematis mahasiswa.
\end{abstract}

Kata Kunci: Problem Posing, Pendekatan Realistik, Kemampuan Komunikasi Matematis.

\begin{abstract}
Many results from researches indicate the low ability of mathematical communication of students as one of the most influential factors is the not optimized applied model. Therefore, a solution is needed to solve the problem and one of the models that can be applied to solve the problem is the problem posing model with realistic approach. The purpose of this research is to know the influence of learning model of problem posing by using realistic approach to student's mathematical communication ability. Sampling technique is conducted by using cluster random sampling and using class B Morning semester II Mathematics Education Study Program as the sample of research. The data collection technique is implemented by using measurement, while the data collection tool used in the research is an essay on mathematical communication ability test. Data analysis technique is conducted by using inferential statistics assisted by SPSS 16 software. Based on the data analysis, the results can be concluded that the model of problem posing learning with realistic approach has a significant effect on students' mathematical communication ability.
\end{abstract}

Keywords: Problem Posing, Realistic Approach, Mathematical Communication Ability

\section{PENDAHULUAN}

Standar isi untuk satuan pendidikan dasar dan menengah mata pelajaran matematika (Permen No. 22 Tahun 2006 tanggal 23 Mei 2006 tentang Standar Isi) disebutkan bahwa pembelajaran matematika bertujuan supaya siswa memiliki kemampuan mengkomunikasikan gagasan dengan simbol, tabel, diagram, atau media lain untuk memperjelas keadaaan atau masalah. Sejalan dengan Permen No 22 tersebut sebagaimana yang diungkapkan oleh National Council of Teacher of Mathematics (2000) bahwa salah satu tujuan pembelajaran matematika diajarkan disekolah adalah komunikasi matematis (mathematical 
communication). Artinya tujuan diajarkannya matematika di sekolah maupun di perguruan tinggi, tidak hanya sekedar bertujuan agar siswa/mahasiswa mampu berhitung dan mengukur saja, tetapi siswa/mahasiswa juga harus mampu mengkomunikasikan apa yang dilihat dan didengar khususnya yang berkaitan dengan matematika. Selain itu, kemampuan komunikasi matematis perlu dikembangkan karena akan membantu siswa maupun mahasiswa dalam memahami dan memperdalam konsep matematika melalui interaksi maupun bertukar pikiran.

Kemampuan komunikasi matematis adalah kemampuan untuk mengekspresikan ide, menggambarkan, dan mendiskusikan konsep matematika secara koheren dan jelas. Kemampuan dalam menjelaskan dan membenarkan suatu prosedur dan proses baik secara lisan maupun tulisan (Lomibao L. S., Luna, C. A. \& Namoco, 2016). Menurut Baroody (Izzati, 2010) dan (Lim, C. S., \& Chew, 2007) ada dua alasan penting mengapa komunikasi menjadi salah satu fokus dalam pembelajaran. Pertama, matematika pada dasarnya adalah bahasa untuk matematika itu sendiri. Matematika bukan hanya alat berpikir yang membantu kita menemukan pola, memecahkan masalah dan menarik kesimpulan, tetapi juga alat untuk mengkomunikasikan pikiran kita, berbagai ide dengan jelas, tepat dan ringkas. Kedua, pembelajaran matematika adalah aktivitas sosial yang melibatkan setidaknya dua pihak, guru dan murid maupun dosen dan mahasiswa. Dalam proses mengajar dan belajar, sangat penting bahwa pemikiran dan ide dikomunikasikan kepada orang lain melalui bahasa. Pada dasarnya pertukaran ide dan pengalaman ini merupakan proses pembelajaran. Selain itu, berkomunikasi dengan teman sebaya sangat penting untuk pengembangan keterampilan komunikasi sehingga dapat belajar berpikir seperti ahli matematika dan memecahkan masalah baru dengan sukses.

Menurut (Kadir, 2008) indikator untuk mengukur kemampuan komunikasi matematis dapat dilihat dari aspek menggambar (drawing), membuat ekspresi matematik (mathematical expression), dan menuliskan jawaban dengan bahasa sendiri (written texts). Menulis (written text) yaitu menjelaskan ide atau solusi dari suatu permasalahan atau gambar dengan menggunakan bahasa sendiri, menggambar (drawing) yaitu menjelaskan ide atau solusi dari permasalahan matematika dalam bentuk gambar, ekspresi matematika (matematical ekpression) yaitu menyatakan masalah atau peristiwa sehari-hari dalam bahasa model matematika (Hodiyanto, H., Budiyono, B., \& Slamet, 2016) dan (Hodiyanto, 2017b).

Berdasarkan hasil penelitian yang dilakukan oleh (Ibrahim, 2011), (Aguspinal, 2011) dan (Hodiyanto, 2017a)menunjukkanbahwakemampuan komunikasi matematis siswa masih rendah, belum sesuai dengan apa yang diharapkan. Selain itu, hasil penelitian yang dilakukan oleh (Haryadi, R. \& Hodiyanto, 2018) terhadap mahasiswa diperoleh bahwa masih rendahnya kemampuan komunikasi matematis mahasiswa IKIP PGRI Pontianak Kalimantan Barat. Dengan demikian, ini menunjukkan bahwa kemampuan komunikasi matematis peserta didik baik siswa maupun mahasiswa masih bermasalah dan perlu diperhatikan, lebih khusus terhadap kemampuan 
komunikasi matematis mahasiswa calon guru yang nantinya akan mendidik dan mengajar siswa-siswinya agar memiliki kemampuan komunikasi yang baik. Salah satu penyebab rendahnya kemampuan komunnikasi matematis adalah model, strategi, maupun model pembelajaran yang selama ini dilakukan oleh pendidik masih bersifat student centered sebagaimana yang diungkapakan oleh (Ansari, 2012).

Permasalahan tersebut tentu perlu dicari solusi agar tidak berlarut-larut dan berakibat tidak mampunya peserta didik untuk bersaing atau berkompetisi dengan siswa maupun mahasiswa di luar negeri dalam menyelesaikan masalah, khususnya masalah-masalah matematiaka. Salah satu cara untuk memperbaiki permasalahan tersebut adalah dengan mencoba salah satu model pembelajaran inovatif yaitu model pembelajaran problem posing (PP). Cai dan Hwang (Kar, T. \& Isik, 2014) mengatakan bahwa model pembelajaran PP didefinisikan sebagai pengajuan masalah baru dan merumuskan kembali dari masalah yang ada. (Suryobroto, 2009) mengatakan bahwa model pembelajaran PP adalah pengajuan masalah-masalah yang dituangkan dalam bentuk pertanyaan. Pertanyaanpertanyaan tersebut kemudian diupayakan untuk dicari jawabannya baik secara individu maupun bersama dengan pihak lain. Dengan demikian, model PP adalah model pembelajaran yang mengharuskan siswa maupun mahasiswa untuk mengajukan pertanyaan-pertanyaan yang lebih sederhana yang mengacu pada penyelesaian soal tersebut.

Dalam penelitian ini model pembelajaran PP akan dimodifikasi dengan pendekatan realistik agar pembelajaran lebih bermakna. Suatu pengetahuan akan menjadi bermakna bagi mahasiswa jika proses pembelajaran dilaksanakan dalam suatu pembelajaran menggunakan permasalahan realistik (Wijaya. A., 2012). Yang dimaksud permasalahan realistik dalam pembelajaran ini bukan berarti permasalah yang harus terkoneksi langsung dengan peserta didik atau yang biasa dikenal dengan masalah kontekstual, tetapi cukup permasalahan yang dapat dibayangkan oleh peserta didik. Model pembelajaran PP sebelum dimodifikasi dengan pendekatan realistik, guru maupun dosen langsung memberikan materi kemudian meminta peserta didiknya untuk mengajukan soal/pertanyaan. Tetapi setelah model pembelajaran PP dimodifikasi dengan pendekatan realistik maka sebelum peserta didik mengajukan pertanyaan, mereka akan diberikan permasalahan realistik untuk diselesaikan sehingga dengan menyelesaikan permasalahan realistik mereka akan memahami konsep yang akan diajarkan oleh guru/dosen dan tentunya berdasarkan bimbingan dan arahan guru maupun dosennya. (Darto, 2013) mengungkapkan bahwa untuk meningkatkan kemampuan komunikasi matematis adalah dengan mengajarkannya dengan pendekatan realistik. Hasil penelitian (Hodiyanto, H., Budiyono, B., \& Slamet, 2016) menunjukkan bahwa setelah model pembelajaran PP dengan pendekatan PMR (realistik) dapat meningkatkan kemampuan komunikasi matematis siswa. Oleh sebab itu, penelitian ini merupakan lanjutan dari penelitian tersebut. Tetapi perbedaannya terletak pada subjek yang akan diteliti. Jika sebelumnya yang menjadi sampel penelitian adalah siswa SMP Negeri, 
namun dalam penelitian ini yang menjadi sampel penelitian adalah mahasiswa. Adapun tujuan dalam penelitian ini adalah untuk mengetahui pengaruh model pembelajaran problem posing dengan pendekatan realistik terhadap kemampuan komunikasi matematis mahasiswa.

\section{METODE}

Metode penelitian yang digunakan dalam penelitian ini adalah penelitian kuantitatif, yang berupa eksperimen semu. Penelitian eksperimen adalah penelitian yang digunakan untuk mencari pengaruh perlakuan tertentu terhadap yang lain dalam kondisi yang dikendalikan (Sugiyono, 2011). Dalam penelitian ini, peneliti ingin mencari pengaruh model pembelajaran problem posing dengan pendekatan realistik terhadap kemampuan komunikasi matematis mahasiswa. Oleh sebab itu, terdapat dua variabel yang digunakan dalam penelitian, variabel bebas dan variabel terikat. Model pembelajaran problem posing dengan pendekatan realistik sebagai variabel bebas, sedangkan kemampuan komunikasi matematis sebagai variabel terikat.

Populasi penelitian ini adalah seluruh mahasiswa semester II Program Studi Pendidikan Matematika Fakultas Pendidikan MIPA dan Teknologi IKIP PGRI Pontianak. Teknik pengambilan sampel menggunakan teknik cluster random sampling. Sampel yang diperoleh adalah mahasiswa kelas B Pagi semester II Program Studi Pendidikan Matematika.
Teknik pengumpul data yang digunakan dalam penelitian ini adalah pengukuran, sedangkan alat pengumpul data yang digunakan adalah tes kemampuan komunikasi matematis yang berupa tes esai. Pemilihan tes esai dilakukan karena kelebihankelebihan yang dimiliki tes esai, yaitu: mudah disiapkan dan disusun, tidak memberikan banyak kesempatan kepada siswa untuk berspekulasi atau untung-untungan, mendorong siswa untuk berani mengemukakan pendapat, memberikan kesempatan kepada siswa untuk mengutarakan maksud dengan menggunakan bahasa dan caranya sendiri, dan dapat diketahui sejauh mana siswa memahami suatu masalah yang diteskan (Arikunto, 2009).

Teknik analisis data dalam penelitian ini menggunakan statistik inferensial (Berbantuan Software SPSS) statistik parametrik jika asumsi atau prasyarat parametrik (data berdistribusi normal) terpenuhi dengan menggunakan uji t test dua sampel berkorelasi. Tetapi jika asumsi tidak terpenuhi maka akan menggunakan uji non parametrik, uji Wilcoxon. Dalam penelitian ini, olah data atau analisis hasil penelitian menggunakan bantuan software SPSS 16.

\section{HASIL DAN PEMBAHASAN}

Berikut ditampilkan hasil peneltian kemampuan komunikasi matematis mahasiswa sebelum (pretest) dan sesudah (posttest) diberikan model pembelajaran problem posing (PP) dengan pendekatan realistik tabel 1.

Tabel 1 Hasil Penelitian Kemampuan Komunikasi Matematis

\begin{tabular}{lcc}
\hline Kemampuan Pembuktian Matematis & Pretest & Posttest \\
\hline Rerata & 32.41 & 64.99 \\
Standar Deviasi & 12.15 & 17.76 \\
\hline
\end{tabular}

H. Hodiyanto, Rahman Haryadi, Pengaruh Model Pembelajaran Problem Posing dengan Pendekatan Realistik Terhadap Kemampuan Komunikasi Matematis Mahasiswa 
Berdasarkan tabel 1 diperoleh bahwa hasil pretest kemampuan komunikasi sebesar 32,41. Ini menunjukkan bahwa kemampuan komunikasi matematis mahasiswa masih rendah. Hasil ini sesuai dengan hasil penelitian (Haryadi, R. \& Hodiyanto, 2018) bahwa kemampuan komunikasi matematis mahasiswa rendah khususnya dalam memperlajari geometri analitik bidang. Tetapi setelah diberikan perlakuan melalui model pembelajaran PP dengan pendekatan realistik, nilai kemampuan komunikasi matematis mahasiswa mengalami peningkatan lebih dari $50 \%$ yaitu 64,99 dengan peningkatan 32,58. Besar peningkatan 32,58 lebih besar dari pada pretest 32,41. Pada gambar 1 di bawah ini menunjukkan peningkatan atau perubahan kemampuan komunikasi matematis mahasiswa sebelum dan sesudah diberikan perlakuan model pembelajaran PP dengan pendekatan realistik.

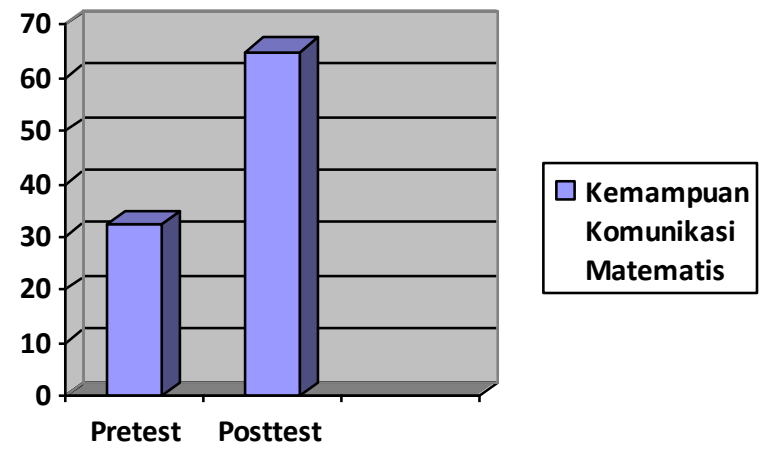

Gambar 1. Rerata Kemampuan Komunikasi Matematis

Selanjutnya akan dilanjutkan uji statistik inferensial untuk mengetahui terdapat pengaruh atau tidaknya model pembelajaran PP dengan pendekatan realistik terhadap kemampuan komunikasi matematis mahasiswa. Berikut akan ditampilkan hasil uji normalitas dengan menggunakan SPSS 16.

Tabel 2 Uji Normalitas dengan Kolmogorov-Smirnov Tests of Normality

\begin{tabular}{llcccccc}
\hline & & \multicolumn{3}{c}{ Kolmogorov-Smirnov $^{\text {a }}$} & \multicolumn{3}{c}{ Shapiro-Wilk } \\
& Kategori & Statistic & $d f$ & Sig. & Statistic & $d f$ & Sig. \\
\hline Nilai & Sebelum & .406 & 29 & .000 & .650 & 29 & .000 \\
Komunikasi & Sesudah & .198 & 29 & .005 & .900 & 29 & .010 \\
\hline
\end{tabular}

a. Lilliefors Significance Correction

Berdasarkan tabel diperoleh bahwa hasil uji nomalitas dengan KolmogorovSmirnov diperoleh bahwa nilai Sig. nilai kemampuan komunikasi matematis sebelum diberikan perlakukan sebesar 0,000 dan nilai Sig. nilai kemampuan komunikasi matematis setelah diberikan perlakukan sebesar 0,005 . Nilai Sig. kedua-duanya kurang dari dari 0,05 sehingga $\mathrm{H} 0$ ditolak dan disimpulkan bahwa kedua data tersebut tidak berdistribusi normal. Oleh sebab 
itu, untuk menguji pengaruh model pembelajaran PP dengan pendekatan realistik tidak bisa menggunakan uji statistik parametric karena asumsi normalitas tidak terpenuhi, sehingga uji inferensial dalam penelitian ini menggunakan uji statistik non parametrik, uji Wilcoxon.

Tabel 3 Ranks Hasil Uji Wilcoxon

\begin{tabular}{cccc}
\hline & $\mathrm{N}$ & $\begin{array}{c}\text { Mean } \\
\text { Rank }\end{array}$ & Sum of Ranks \\
\hline Sesudah - Sebelum Negative Ranks & $0^{\mathrm{a}}$ & .00 & .00 \\
Positive Ranks & $29^{\mathrm{b}}$ & 15.00 & 435.00 \\
Ties & $0^{\mathrm{c}}$ & & \\
Total & 29 & & \\
\hline
\end{tabular}

a. Sesudah $<$ Sebelum

b. Sesudah $>$ Sebelum

c. Sesudah $=$ Sebelum

Tabel 4 Statistik Uji Wilcoxon

\begin{tabular}{lc}
\multicolumn{2}{c}{ Test Statistics $^{\text {b }}$} \\
\hline Z & Sesudah - Sebelum \\
\hline Asymp. Sig. (2-tailed) & $-4.716^{\mathrm{a}}$ \\
\hline a. Based on negative ranks. & .000 \\
b. Wilcoxon Signed Ranks Test &
\end{tabular}

Dasar pengambilan kesimpulan dari uji Wilcoxon pada tabel 4 berdasarkan uji z. Jika nilai z hitung (angka $\mathrm{z}$ output) $>$ nilai $\mathrm{z}$ tabel (tabel $\mathrm{z}$ ) maka $\mathrm{H} 0$ berada di daerah penolakan dan sebaliknya jika nilai z hitung (angka $\mathrm{z}$ output) $<$ nilai z tabel (tabel z) maka H0 berada di daerah penerimaan. Pada tabel 4 didapat nilai z hitung adalah -4,716, sedangkan $\mathrm{z}$ tabel bisa dihitung pada tabel $\mathrm{z}$ dengan $\alpha=5 \%$ maka luas kurva normal adalah $50 \%-5 \%=45 \%$ atau 0,45 . Pada tabel $\mathrm{z}$, untuk luas 0,45 didapatt angka $\mathrm{z}$ tabel sekitar -1,645 (tanda “_“" menyesuaikan dengan nilai $\mathrm{z}$ output atau bisa diabaikan) (Santoso, 2010). Karena $Z$ hitung $>\mathrm{z}$ tabel $(4,716>1,645)$ maka H0 berada di daerah penolakan atau
$\mathrm{H} 0$ ditolak yang artinya $\mathrm{Ha}$ diterima. Artinya model pembelajaran PP dengan pendekatan realistik berpengaruh terhadap kemampuan komunikasi matematis mahasiswa.

Selain itu, pengambilan keputusan dapat dilihat dari probabilitas atau nilai sig. (2 tailed). Jika probabilitas $>0,05$ maka $\mathrm{H} 0$ diterima dan sebaliknya jika probabilitas < 0,05 maka H0 ditolak. Berdasarkan tabel 4 terlihat bahwa pada kolom asymp. sig. (2 tailed)/asymptotic significance untuk uji dua ekor adalah 0.000. Karena dalam penelitian ini uji satu ekor maka probabilitas menjadi $0.000 / 2=0.000$. Dari hasil ini diperoleh bahwa probabilitas di bawah $0,05(0,005$ $<0,05)$ maka H0 ditolak. Berdasarkan

H. Hodiyanto, Rahman Haryadi, Pengaruh Model Pembelajaran Problem Posing dengan Pendekatan Realistik Terhadap Kemampuan Komunikasi Matematis Mahasiswa 
hasil penelitian menunjukkan bahwa model pembelajaran PP dengan pendekatan realistik berpengaruh yang signifikan terhadap kemampuan komunikasi matematis mahasiswa. Hasil penelitian ini sesuai dengan hasil penelitian (Hodiyanto, H., Budiyono, B., \& Slamet, 2016) bahwa kemampuan komunikasi matematis siswa yang diajarkan dengan model pembelajaran PP dengan pendekatan realistik lebiih baik dari pada kemampuan komunikasi matematis siswa yang diajarkan dengan model pembelajaran langsung serta sejalan dengan pendapat (Clark, K. K., Jacobs, J., Pittman, M.E., \& Borko, 2005) yang menyatakan bahwa salah satu strategi pembelajaran yang dapat digunakan untuk meningkatkan kemampuan komunikasi matematis adalah strategi PP. Hasil penelitian ini disebabkan model pembelajaran PP menuntut mahasiswa untuk berdiskusi dan bertukar pikiran dalam pengajuan dan penyelesaian soal yang diajukan temannya. Komunikasi antar teman dalam pengajuan dan pemecahan soal mengakibatkan kemampuan komunikasi matematis mahasiswa semakin baik dan pemahaman terhadap materi yang akan dipelajari semakin dalam dan jelas.

Menurut (Suryobroto, 2009) model pembelajaran PP dapat memotivasi peserta didik untuk berpikir kritis, kreatif, dan interaktif. Dengan demikian, mahasiswa yang berpikir kritis, kreatif, dan interaktif akan mengakibatkan meningatkan kemampuan komunikasi matematis mahasiswa. Mahasiswa yang kreatif tentu memiliki banyak ide yang baru sehingga mendorong mahasiswa untuk menuliskan dan mengkomunikasikan ide tersebut dengan caranya sendiri (aspek written text dalam kemampuan komunikasi matematis). selain itu, dalam penelitian model pembelajaran PP dimodifikasi dengan pendekatan realistik. Pendekatan realitik juga mendorong mahasiswa untuk mangkomunikasikan ide-idenya karena pendekatan realistik mahasiswa diajukan permasalah oleh dosen untuk diselesaikan dalam memahami konsep yang akan diajarkan dan tentunya dalam penyelesaian permasalahan realistik tersebut mahasiswa harus mampu mengkomunikasikan atau mendiskusikan permasalahan tersebut dengan teman-teman kelompoknya dalam penyelesaian masalah. Semakin banyak ide yang diajukan oleh mahasiswa dalam penyelesaian masalah maka kemampuan komunikasi matematis mereka semakin lebih baik.

\section{SIMPULAN}

Berdasarkan hasil penelitian dan pembahasan yang telah diuraikan maka dalam penelitian ini dapat disimpulkan bahwa model pembelajaran PP dengan pendekatan realistik berpengaruh yang signifikan terhadap kemampuan komunikasi matematis mahasiswa. Penelitian ini dapat dilanjutkan oleh penelitian lain dengan menerapkan model pembelajaran PP dengan pendekatan realistik untuk mengembangkan berpikir tingkat tinggi (HOTS) yang lain karena kemampuan komunikasi termasuk bagian dari HOTS. Selain itu, model pembelajaran PP dengan pendekatan realistik terhadap kemampuan komunikasi matematis dapat dilanjutkan dengan dilihat atau ditinjau dari soft skill maupun dari kemampuan spasial karena berdasarkan beberapa hasil penelitian kemampuan spasial berpengaruh terhadap hasil belajar geometri. 
Terima kasih kami sampaikan kepada KEMENRISTEKDIKTI atas dana Hibah Penelitian Dosen Pemula Tahun Anggaran 2018 yang telah diberikan serta Program Studi Pendidikan Matematika IKIP-PGRI Pontianak yang telah menjadi mitra dalam kegiatan penelitian ini.

\section{DAFTAR PUSTAKA}

Aguspinal. (2011). Peningkatan Kemampuan Berpikir Kreatif dan Komunikasi Matematis Siswa SMA Melalui Pendekatan Open-Ended dengan Strategi Group-To-Group. Bandung: UPI.

Ansari, B. I. (2012). Komunikasi Matematik dan Politik. Banda Aceh: Yayasan Pena.

Arikunto, S. (2009). Dasar-Dasar Evaluasi Pendidikan. Jakarta: Bumi Aksara.

Clark, K. K., Jacobs, J., Pittman, M.E., \& Borko, H. (2005). Strategies for Building Mathematical Communication in the Middle School Classroom: Modeled in Professional Development, Implemented in the Classroom. CIMLE, 11(2), 1-12.

Darto, H. (2013). Improving The Communication Mathematics Ability By using Realistic Mathematics Education Approach. In Korea Society Of Mathematical Education Conference. (pp. 647657). Korea.

Haryadi, R. \& Hodiyanto, H. (2018). Diskripsi Kemampuan Komunikasi Matematis Mahasiswa. In Seminar Nasional Penerapan Ilmu Pengetahuan dan Teknologi (PIPT). Pontianak: UNTAN: Pontianak.

Hodiyanto, H., Budiyono, B., \&
Slamet, I. (2016). Eksperimentasi Model Pembelajaran Problem Posing Dan Problem Solving Dengan Pendekatan Pmr Terhadap Prestasi Belajar Dan Kemampuan Komunikasi Matematis Ditinjau Dari Kreativitas Siswa Kelas Vii Smp Negeri Di Kabupaten Sukoharjo. Jurnal Pembelajaran Matematika, 4(2).

Hodiyanto, H. (2017a). Kemampuan Komunikasi Matematis Dalam Pembelajaran Matematika. Jurnal Ilmiah Pendidikan Matematika, Ilmu Matematika Dan Matematika Terapan, 7(1), 9-18.

Hodiyanto, H. (2017b). Pengaruh model pembelajaran problem solving terhadap kemampuan komunikasi matematis ditinjau dari gender. Jurnal Riset Pendidikan Matematika, 4(2), 219-228.

Ibrahim. (2011). Peningkatan Kemampuan Komunikasi, Penalaran, dan Pemecahan Masalah Matematis Serta Kecerdasan Emosional Melalui Pembelajaran Berbasis-Masalah Pada Siswa Sekolah Menengah. UPI Bandung.

Izzati, N. (2010). Komunikasi Matematik dan Pendidikan Matematika. Seminar Nasional Matematika dan Pendidikan Matematika. Yogyakarta: UNY: Yogyakarta.

Kadir. (2008). Kemampuan Komunikasi Matematik dan Keterampilan Sosial Siswa Dalam Pembelajaran Matematika. In Seminar Nasional Matematika dan Pendidikan Matematika (pp. 339-350). Yogyakarta.: UNY: Yogyakarta.

Kar, T. \& Isik, C. (2014). Analysis of Problem Posed by Pre-Service Primary Teachers About Adding

H. Hodiyanto, Rahman Haryadi, Pengaruh Model Pembelajaran Problem Posing dengan Pendekatan Realistik Terhadap Kemampuan Komunikasi Matematis Mahasiswa 
Fraction in Termof Semantic Sugiyono. (2011). Metode Penelitian Structure. Internationl Society of Pendidikan (Pendekatan KuanEducatinal Research., 2, 135-146. titatif, Kualitatif, dan R\&D). Lim, C. S., \& Chew, C. M. (2007). Mathematical Communication in Malaysian Bilingual Classrooms. In In Paper APEC-Tsukuba International Conference (pp. $1-2)$.

Lomibao, L. S., Luna, C. A. \& Namoco, R. A. (2016). The Influence of Mathematical Communication on Students' Mathematics Performance and Anxiety. American Journal of Educational Research, 4(5), 378-382. Bandung: Alfabeta.

Suryobroto. (2009). Proses Pembelajaran di Sekolah. Jakarta: PT Asdi Mahasatya.

Wijaya. A. (2012). Pendidikan Matematika Realistik Suatu Alternatif Pendekatan Pembelajaran Matematika. Yogyakarta: Graha Ilmu. 